\title{
Upregulation of the transcription factor TFAP2D is associated with aggressive tumor phenotype in prostate cancer lacking the TMPRSS2:ERG fusion
}

Christoph Fraune ${ }^{1 \dagger}$, Luisa Harms ${ }^{1 \dagger}$, Franziska Büscheck ${ }^{1}$, Doris Höflmayer ${ }^{1}$, Maria Christina Tsourlakis ${ }^{1}$,

Till S. Clauditz ${ }^{1}$, Ronald Simon ${ }^{1 *}$ D, Katharina Möller ${ }^{1}$, Andreas M. Luebke', Christina Möller-Koop ${ }^{1}$, Stefan Steurer ${ }^{1}$, Claudia Hube-Magg', Guido Sauter', Sören Weidemann', Patrick Lebok', David Dum', Simon Kind', Sarah Minner ${ }^{1}$, Jakob R. Izbicki ${ }^{2}$, Thorsten Schlomm³ ${ }^{3}$ Hartwig Huland ${ }^{4}$, Hans Heinzer ${ }^{4}$, Eike Burandt ${ }^{1}$, Alexander Haese ${ }^{4}$,

Markus Graefen ${ }^{4}$ and Cornelia Schroeder ${ }^{2}$

\begin{abstract}
Background: TFAP2D is a transcription factor important for modulating gene expression in embryogenesis. Its expression and prognostic role in prostate cancer has not been evaluated.

Methods: Therefore, a tissue microarray containing 17,747 prostate cancer specimens with associated pathological, clinical, and molecular data was analyzed by immunohistochemistry to assess the role of TFAP2D.

Results: TFAP2D expression was typically increased in prostate cancer as compared to adjacent non-neoplastic glands. TFAP2D staining was considered negative in $24.3 \%$ and positive in $75.7 \%$ of 13,545 interpretable cancers. TFAP2D staining was significantly linked to advanced tumor stage, high classical and quantitative Gleason grade, lymph node metastasis, and a positive surgical margin ( $p \leq 0.0045)$. TFAP2D positivity was more common in ERG fusion positive (88.7\%) than in ERG negative cancers (66.8\%; $p<0.0001)$. Subset analyses in 3776 cancers with and 4722 cancers without TMPRSS2:ERG fusion revealed that associations with tumor phenotype and patient outcome were largely driven by the subset of ERG negative tumors. Multivariate analysis did not identify TFAP2D protein expression levels as a robust independent prognostic parameter. Positive TFAP2D immunostaining was significantly associated with 10 of 11 previously analyzed chromosomal deletions in ERG negative cancers ( $p \leq 0.0244$ each) indicating that elevated TFAP2D expression parallels genomic instability in prostate cancer.
\end{abstract}

Conclusion: These data demonstrate that TFAP2D protein overexpression is linked to prostate cancer progression and genomic instability in ERG negative prostate cancers.

Keywords: TFAP2D, prostate cancer, genomic instability, prognosis, immunohistochemistry, tissue micro array

\footnotetext{
* Correspondence: R.Simon@uke.de

${ }^{+}$Christoph Fraune and Luisa Harms contributed equally to this work. 1 Institute of Pathology, University Medical Center Hamburg-Eppendorf,

Martinistr 52, 20246 Hamburg, Germany

Full list of author information is available at the end of the article
}

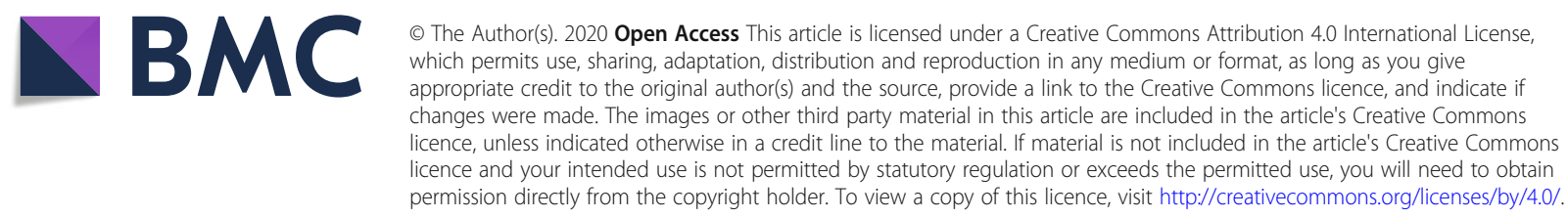




\section{Introduction}

Prostate cancer is the most prevalent cancer in men in developed countries and is clinically characterized by a broad spectrum of tumor phenotype from incidentally discovered and clinically silent tumors to highly aggressive and metastasizing tumors with significant mortality (Bray et al. 2018). To predict tumor behavior, clinical parameters such as serum PSA-levels as well as histopathologic criteria, especially Gleason tumor grading, are widely used. However, these methods may lack reliable prediction of disease course in individual cases. To more reliably prevent unnecessary treatments better prognostic molecular markers are needed.

The transcription factor AP-2 family consists of five isoforms (AP- $2 \alpha$ to AP- $2 \varepsilon$ ) that modulate gene expression after dimerization via binding to palindromic GCrich sequences in promotor and enhancer regions of various genes that impart cellular proliferation and differentiation (Eckert et al. 2005; Williams and Tjian 1991). An essential role in embryology/organ development, especially for neuronal/neuroectodermal tissue (AP2 $\alpha, \mathrm{AP} 2 \beta, \mathrm{AP} 2 \gamma, \mathrm{AP} 2 \delta$ ) but also in the kidney (AP2 $\beta, A P 2 \gamma)$, eye (Ap2 $\delta$ ) and olfactoric bulb (AP2 $\varepsilon$ ) with varying redundancy between the isoforms was reported (Zhao et al. 2003; Moser et al. 1997a; Feng and Williams 2003; Moser et al. 1997b; Werling and Schorle 2002). The isoform AP-2 $\delta$ (TAFP2D) is also expressed in adult tissue of the male genital tract, namely in the prostate and with less abundance in testicular tissue (Cheng et al. 2002).

Few reports have analyzed the role of AP-2 family members in tumorigenesis. In this context, most studies focus on breast cancer, where AP-2 responsive elements were found in the estrogen receptor gene (ESR1) and the cERBB2 gene (HER2/neu). Upregulation of AP-2 in cancer cell was detected, and tumor progression in a murine model of breast cancer with AP-2 $\gamma$ overexpression was reported (Turner et al. 1998; Bosher et al. 1996; Jager et al. 2005; Pellikainen et al. 2004). TFAP2G is also overexpressed in germ cell tumors (and its precursor in-situ lesion) of the testis, supporting the notion of oncofetal properties of AP-2 family members (Pauls et al. 2005).

Based on the reported role of TFAP2D in prostate tissue and the implications of AP-2 family members in neoplasia (Cheng et al. 2002), we aimed to determine the potential role of varying TFAP2D expression levels in prostate cancer. For this purpose, TFAP2D protein expression was successfully analyzed in 13,545 of 17,747 prostate cancers that were available in a tissue microarray format.

\section{Materials and methods}

\section{Patients}

Radical prostatectomy specimens were available from 17, 747 patients, undergoing surgery between 1992 and 2015 at the Department of Urology and the Martini Clinic at the University Medical Center Hamburg-Eppendorf. Histological analysis was performed in standardized manner including complete embedding of the entire prostate (Schlomm et al. 2008). Histopathological data were retrieved from the patients' records, including tumor stage, Gleason grade, nodal stage, and status of the resection margin. "Quantitative" Gleason grading was performed as described (Sauter et al. 2016). In brief, for every prostatectomy specimen, the percentages of Gleason 3, 4, and 5 patterns were recorded in cancerous tissues as part of the regular process of Gleason grading. Gleason $3+4$ and $4+$ 3 cancers were subdivided according to their percentage of Gleason 4. For practical use, cancers within the $3+4$ and $4+3$ categories were allocated into 8 subgroups: $3+$ $4 \leq 5 \%$ Gleason $4,3+4$ 6-10\%, $3+411-20 \%, 3+421-$ $30 \%, 3+4$ 31-49\%, $4+350-60 \%, 4+361-80 \%$ and $4+$ $3>80 \%$ Gleason 4 . Separate groups were defined for cancers with tertiary Gleason 5 pattern, including $3+4$ Tert. 5 and $4+3$ Tert.5. From 14,464 patients follow-up data with a mean follow-up of 56.3 months was available (median 48; Table 1). Prostate specific antigen (PSA) values were measured subsequent to surgery. PSA recurrence was defined as the time point when postoperative PSA was at least $0.2 \mathrm{ng} / \mathrm{ml}$ and an PSA increase at subsequent measurements was observed. The TMA manufacturing process was described earlier in detail (Kononen et al. 1998). In short, a single $0.6 \mathrm{~mm}$ tissue core was taken from one donor tissue block of each patient. The donor block was merely selected for high tumor cell content, but not for a particular tumor focus or Gleason pattern in order to avoid a potential selection bias towards focal but potentially non-representative tumor areas. The tissues were distributed among 27 TMA blocks, each containing 144 to 522 tumor samples. For internal controls, each TMA block also contained various control tissues, including normal prostate tissue. The molecular database attached to the TMA contained previously compiled data on ERG expression in 10,678 (Weischenfeldt et al. 2013), ERG break-apart FISH analysis in 7099 (expanded from (Minner et al. 2011), Ki67-labeling index in 4426 (expanded from (Minner et al. 2010), androgen receptor (AR) expression in 7856 cancers (Weischenfeldt et al. 2013) and deletion status of 3p14 (FOXP1) in 7201 cases (expanded from (Krohn et al. 2013), 5q21 (CHD1) in 8074 (expanded from (Burkhardt et al. 2013), 6q15 (MAP 3 K7) in 6069 cases (expanded from (Kluth et al. 2013), 8p21 in 7001 cases (expanded from (Kluth et al. 2017), PTEN (10q23) in 6803 cases (expanded from (Krohn et al. 2012), 12p13 (CDKN1B) in 6187 cases (expanded from (Kluth et al. 2015a), 12q24 in 7435 cases (expanded from (Weischenfeldt et al. 2013), 13q14 in 7499 cases (expanded from (Kluth et al. 2018), 16q24 in 5493 cases (expanded from (Kluth et al. 2015b), 17p13 (TP53) in 8307 cases 
Table 1 Composition of the prostate prognosis tissue microarray. Percentage in the column "Study cohort on TMA" refers to the fraction of samples across each category. Percentage in column "Biochemical relapse among categories" refers to the fraction of samples with biochemical relapse within each parameter in the different categories

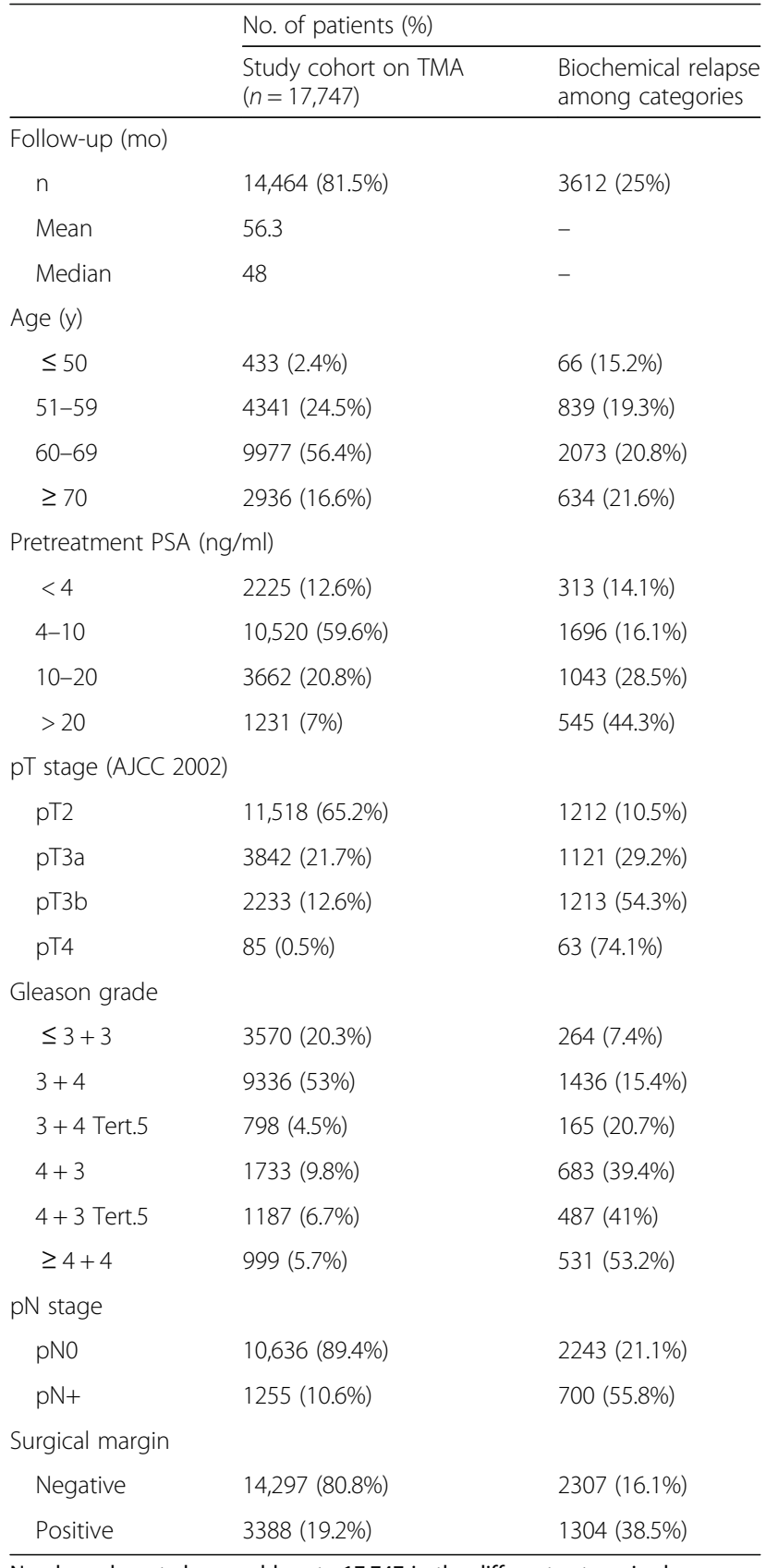

Numbers do not always add up to 17,747 in the different categories because of cases with missing data. Abbreviation: AJCC American Joint Committee on Cancer

(expanded from (Kluth et al. 2014), and 18q21 in 7032 cases (expanded from (Kluth et al. 2016). The usage of archived diagnostic left-over tissues for manufacturing of tissue microarrays, their analysis for research purposes and patient data analysis has been approved by local laws
(HmbKHG, $\$ 12,1)$ and by the local ethics committee (Ethics commission Hamburg, WF-049/09). All work has been carried out in compliance with the Helsinki Declaration.

\section{Immunohistochemistry}

TMA sections were freshly cut and immunostained on 1 day and in one experiment. Slides were exposed to heatinduced antigen retrieval for $5 \mathrm{~min}$ in an autoclave at $121^{\circ} \mathrm{C}$ in $\mathrm{pH} 7.8$ Tris-EDTA buffer after deparaffinization. Primary antibody specific for Anti-TFAP2D (rabbit polyclonal antibody, Sigma-Aldrich, St. Louis, Missouri, USA, HPA048962; dilution 1:150) was applied at $37^{\circ} \mathrm{C}$ for $60 \mathrm{~min}$. Bound antibody was then visualized using the EnVision Kit (Dako, Glostrup, Denmark) according to the manufacturer's directions. TFAP2D staining was mainly nuclear, however, often accompanied by weak to moderate cytoplasmic staining. Nuclear staining was scored in this study because of the known nuclear function of TFAP2D. As TFAP2D typically stained the nucleus in all $(100 \%)$ tumor cells of a TFAP2D positive tissue spot, only the staining intensity was assessed in a four-step scale including negative, weak $(1+)$, moderate $(2+)$, and strong $(3+)$ staining.

\section{Statistics}

For statistical analysis JMP ${ }^{\star} 12$ software (SAS Institute Inc., NC, USA) was used. $\mathrm{Chi}^{2}$-test and contingency tables were performed to check for associations between molecular parameters and tumor phenotype. Cox proportional hazards regression analysis was performed to test the statistical independence and significance between pathological, molecular and clinical variables. Separate analyses were performed using different sets of parameters available either before or after prostatectomy. Survival curves were calculated according to Kaplan-Meier. The Log-Rank test was performed to find significant differences between groups.

\section{Results}

Technical issues

A total of 13,545 of 17,747 tumor samples (76.3\%) were interpretable in our TMA analysis. Reasons for noninformative cases $(n=4202 ; 23.7 \%)$ included lack of tissue samples or absence of unequivocal cancer tissue in the TMA spot.

\section{TFAP2D expression in normal and cancerous prostate tissues}

In normal prostate glands, nuclear TFAP2D staining intensity ranged from negative to moderate in luminal and basal cells. In prostate cancers, nuclear staining was seen in 10,259 of our 13,545 (75.7\%) interpretable tumors. TFAP2D staining was considered weak in $73.4 \%$, moderate in $2.3 \%$, and strong in $<0.1 \%$ of cancers. Because of 
the low number of cases with moderate and strong staining $(n=313)$, tumors were classified as TFAP2D positive (any staining) and negative for all statistical analyses. Tissue spots containing both normal and cancerous glands usually showed higher TFAP2D levels in the tumor cells than in normal glands. Tumors with negative findings typically also lacked TFAP2D staining in the adjacent normal tissues. Representative micrographs depicting nuclear TFAP2D immunostaining are given in Fig. 1.

\section{TFAP2D expression and tumor phenotype}

TFAP2D staining was significantly associated with adverse tumor features, including advanced tumor stage, high Gleason grade, presence of lymph node metastasis $(p<0.0001$ each) and a positive surgical margin $(p=0.0045$, Table 2$)$.

\section{TFAP2D and TMPRSS2:ERG fusion status}

Data on TMPRSS2:ERG fusion status obtained by FISH were available from 5636 and by immunohistochemistry from 8325 tumors with evaluable TFAP2D immunostaining. A concordant result of IHC and FISH determined ERG status was found in 5291 of 5535 (95.6\%) cancers for which both data were available. High TFAP2D expression was strongly linked to TMPRSS2: ERG rearrangement and ERG expression: TFAP2D positivity increased from $66.5-73.5 \%$ in ERG negative cancers (by IHC or FISH) to $88.2-89.8 \%$ in ERG positive cancers $(p<0.0001$ each, Fig. 2). Because of the strong link between increased TFAP2D levels and ERG rearrangement, the impact of TFAP2D expression on tumor phenotype and prognosis was separately analyzed in ERG fusion positive and negative cancers. This analysis revealed that the observed associations were largely caused by the subset of ERG negative cancers, while TFAP2D staining was unrelated to the analyzed features in ERG positive cancers (Table 2). This especially held true for associations with patient outcome. Detectable TFAP2D expression was strongly linked to outcome in ERG negative cancers $(p<0.0001$, Fig. 3b) but completely unrelated to patient outcome in ERG positive cancers $(p=0.9543$, Fig. $3 c)$.

\section{TFAP2D and chromosomal deletions}

Chromosomal deletions were generally more frequent in TFAP2D positive than negative cancers (Fig. 4). This observation was particularly strong in ERG negative cancers, where it reached statistical significance in 10 out of 11 deletions (Fig. 4b). This association was much less strong in ERG positive cancers where it only reached statistical significance for 3p14, and 12p13, and 16q24 (Fig. 4c).

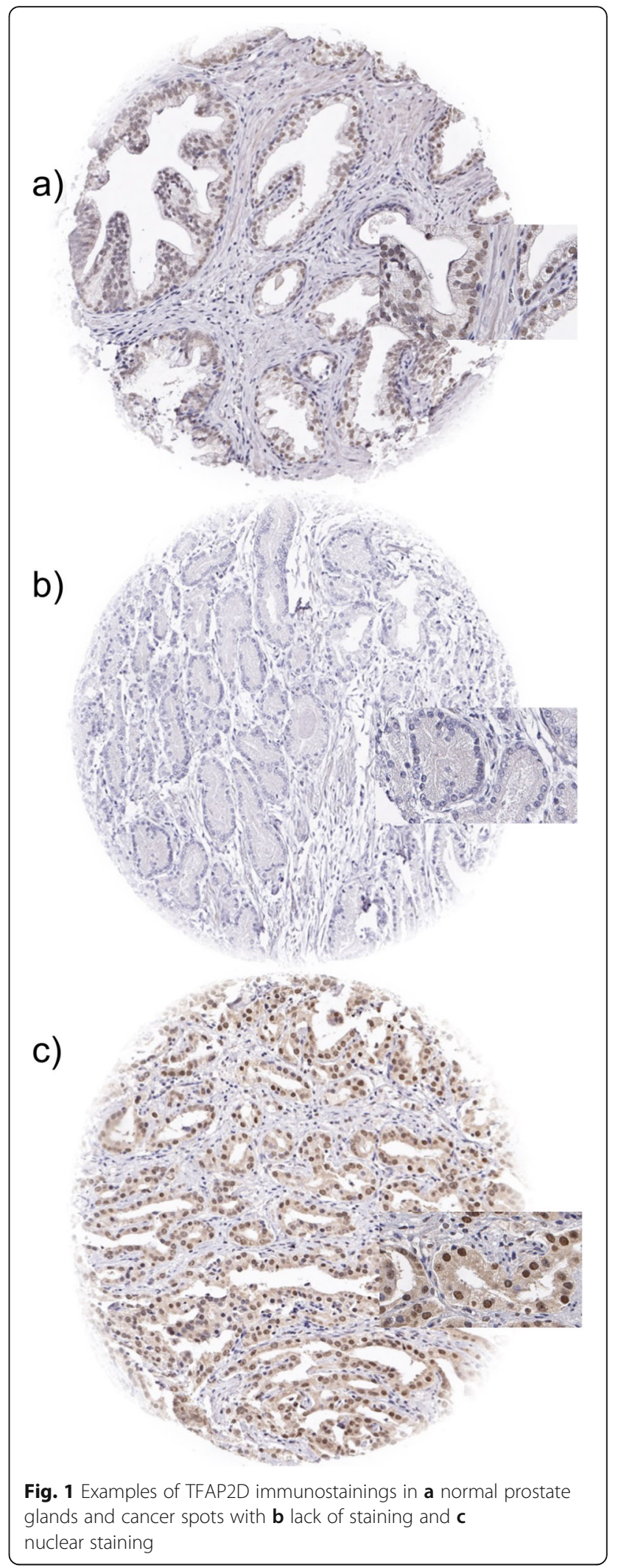


Table 2 TFAP2D immunostaining results and prostate cancer phenotype in all cancers, ERG negative cancers, and ERG positive cancers

\begin{tabular}{|c|c|c|c|c|c|c|c|c|c|c|c|c|}
\hline & \multicolumn{4}{|c|}{ TFAP2D IHC result all cancers } & \multicolumn{4}{|c|}{$\begin{array}{l}\text { TFAP2D IHC result in ERG } \\
\text { negative cancers }\end{array}$} & \multicolumn{4}{|c|}{$\begin{array}{l}\text { TFAP2D IHC result in ERG } \\
\text { positive cancers }\end{array}$} \\
\hline & $\begin{array}{l}n \\
13545\end{array}$ & $\begin{array}{l}\text { negative } \\
(\%) \\
24.3\end{array}$ & $\begin{array}{l}\text { positive } \\
(\%) \\
75.7\end{array}$ & $p$ value & $\begin{array}{l}n \\
4722\end{array}$ & $\begin{array}{l}\text { negative (\%) } \\
33.2\end{array}$ & $\begin{array}{l}\text { positive (\%) } \\
66.8\end{array}$ & $p$ value & $\begin{array}{l}n \\
3776\end{array}$ & $\begin{array}{l}\text { negative (\%) } \\
11.3\end{array}$ & $\begin{array}{l}\text { positive (\%) } \\
88.7\end{array}$ & $p$ value \\
\hline \multicolumn{13}{|l|}{ Tumor stage } \\
\hline pT2 & 8569 & 26.6 & 73.4 & $<0.0001$ & 3114 & 35.3 & 64.7 & $<0.0001$ & 2268 & 11.3 & 88.7 & 0.8159 \\
\hline рТ3а & 3054 & 21.9 & 78.1 & & 982 & 32.4 & 67.6 & & 998 & 10.8 & 89.2 & \\
\hline pT3b-4 & 1866 & 17.1 & 82.9 & & 612 & 23.2 & 76.8 & & 495 & 11.9 & 88.1 & \\
\hline \multicolumn{13}{|l|}{ Gleason grade } \\
\hline$\leq 3+3$ & 2391 & 31.8 & 68.2 & $<0.0001$ & 865 & 42.7 & 57.3 & $<0.0001$ & 725 & 14.3 & 85.7 & 0.0256 \\
\hline $3+4$ & 7246 & 24.7 & 75.3 & & 2530 & 34 & 66 & & 2203 & 10.9 & 89.1 & \\
\hline $3+4$ Tert. 5 & 648 & 22.8 & 77.2 & & 216 & 29.6 & 70.4 & & 117 & 11.1 & 88.9 & \\
\hline $4+3$ & 1354 & 18.8 & 81.2 & & 518 & 25.3 & 74.7 & & 374 & 8.8 & 91.2 & \\
\hline $4+3$ Tert. 5 & 988 & 15.9 & 84.1 & & 305 & 23.9 & 76.1 & & 211 & 7.6 & 92.4 & \\
\hline$\geq 4+4$ & 809 & 18.3 & 81.7 & & 284 & 23.6 & 76.4 & & 143 & 13.3 & 86.7 & \\
\hline \multicolumn{13}{|c|}{ Gleason grade quant } \\
\hline $3+4 \leq 5 \%$ & 1839 & 27.8 & 72.2 & $<0.0001$ & 673 & 37.7 & 62.3 & $<0.0001$ & 550 & 12.7 & 87.3 & 0.0636 \\
\hline $3+46-10 \%$ & 1811 & 25.1 & 74.9 & & 663 & 34.5 & 65.5 & & 582 & 10.3 & 89.7 & \\
\hline $3+411-20 \%$ & 1609 & 23.8 & 76.2 & & 574 & 34.3 & 65.7 & & 488 & 9.4 & 90.6 & \\
\hline $3+421-30 \%$ & 825 & 21.6 & 78.4 & & 288 & 29.2 & 70.8 & & 284 & 9.2 & 90.8 & \\
\hline $3+431-49 \%$ & 682 & 22.1 & 77.9 & & 256 & 30.9 & 69.1 & & 209 & 12 & 88 & \\
\hline $4+350-60 \%$ & 564 & 19.5 & 80.5 & & 216 & 26.9 & 73.1 & & 168 & 8.3 & 91.7 & \\
\hline $4+361-80 \%$ & 495 & 17.6 & 82.4 & & 206 & 23.8 & 76.2 & & 143 & 7.7 & 92.3 & \\
\hline $4+3>80 \%$ & 125 & 16 & 84 & & 52 & 19.2 & 80.8 & & 33 & 12.1 & 87.9 & \\
\hline \multicolumn{13}{|c|}{ Lymph node metastasis } \\
\hline No & 8141 & 23.8 & 76.2 & $<0.0001$ & 2725 & 32.6 & 67.4 & $<0.0001$ & 2142 & 11.4 & 88.6 & 0.4192 \\
\hline $\mathrm{N}+$ & 1032 & 15.6 & 84.4 & & 285 & 20.7 & 79.3 & & 242 & 13.2 & 86.8 & \\
\hline \multicolumn{13}{|c|}{ Preop. PSA level (ng/ml) } \\
\hline$<4$ & 1624 & 21.6 & 78.4 & 0.0101 & 487 & 30.4 & 69.6 & 0.2017 & 526 & 10.6 & 89.4 & 0.012 \\
\hline $4-10$ & 7988 & 24.2 & 75.8 & & 2797 & 33.6 & 66.4 & & 2332 & 10.2 & 89.8 & \\
\hline $10-20$ & 2846 & 24.8 & 75.2 & & 1033 & 31.8 & 68.2 & & 661 & 14.1 & 85.9 & \\
\hline$>20$ & 1008 & 27.1 & 72.9 & & 384 & 36.5 & 63.5 & & 231 & 15.2 & 84.8 & \\
\hline \multicolumn{13}{|l|}{ Surgical margin } \\
\hline negative & 10,764 & 24.8 & 75.2 & 0.0045 & 3743 & 33.6 & 66.4 & 0.2278 & 2983 & 11.5 & 88.5 & 0.4099 \\
\hline positive & 2732 & 22.2 & 77.8 & & 967 & 31.5 & 68.5 & & 777 & 10.4 & 89.6 & \\
\hline
\end{tabular}

TFAP2D, tumor cell proliferation (Ki67 labeling index) and androgen receptor (AR) expression

TFAP2D staining was significantly linked to increased cell proliferation as determined by Ki67 labeling index (Table 3). This association was independent of Gleason grading $(p<0.0001)$ and also held true for most analyzed subgroups with identical Gleason score $(p \leq 0.0025$ each). There was a strong positive association between AR expression and presence of nuclear TFAP2D staining $(p<0.0001$, Fig. 5). Whereas nuclear TFAP2D staining was observed in $35.9 \%$ of tumors with negative AR expression, $90.9 \%$ of tumors with strong AR expression were TFAP2D positive. The observed association held true for both ERG positive and ERG negative subgroups and was particularly evident in the ERG negative subgroup $(p<0.0001$ each).

\section{TFAP2D expression and PSA recurrence}

Follow-up data were available from 10,801 patients with interpretable TFAP2D immunostaining. Nuclear TFAP2D 


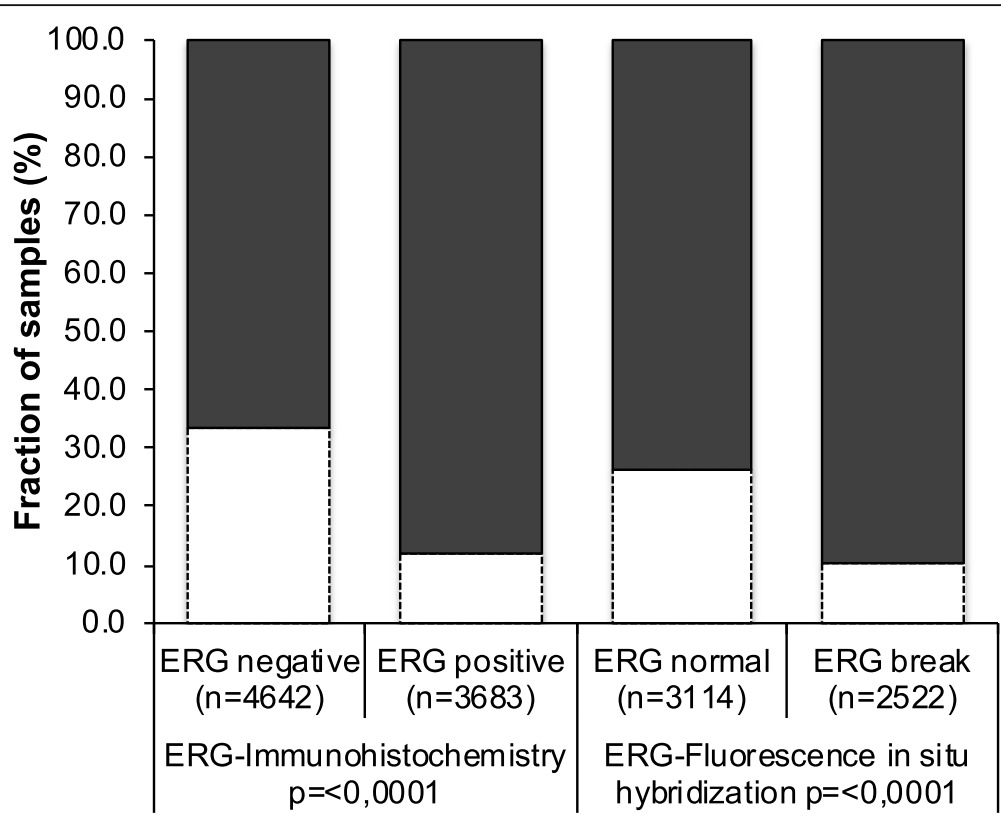

TFAP2D negative

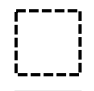

TFAP2D positive

Fig. 2 Association between positive TFAP2D immunostaining and ERG-status (IHC/FISH) in all cancers

staining was linked to early biochemical recurrence $(p<$ 0.0001, Fig. 3a). Subset analyses of ERG positive and ERG negative cancers revealed that the prognostic impact of TFAP2D expression was driven by the ERG-negative group ( $p<0.0001$, Fig. 3b). TFAP2D expression was unrelated to patient outcome in ERG-positive cancers ( $p=$ 0.9453, Fig. 3c). A further analysis based on subsets of all cancers with identical classical and quantitative Gleason grades revealed no significant prognostic impact of TFAP2D expression for any Gleason group (Additional Figure 1).

\section{Multivariate analysis}

Four different multivariate analyses were performed to investigate the clinical relevance of TFAP2D immunostaining in different scenarios. Scenario 1 evaluated all postoperatively available prognostic parameters including $\mathrm{pT}, \mathrm{pN}$, surgical margin status, preoperative PSA value and prostatectomy Gleason grade. In scenario 2, the same postoperatively available parameters were included with the exception of $\mathrm{pN}$. This was because the indication and extent of lymph node dissection is not standardized in the surgical therapy of prostate cancer, which may introduce a bias towards high grade cancers. The next two scenarios were to model the preoperative situation to the best possible extent. Scenario 3 included TFAP2D immunostaining, preoperative serum PSA, clinical tumor stage (cT) and the prostatectomy Gleason grade. Since postoperative determination of the Gleason grade is superior to the preoperative biopsy Gleason grade (subjected to sampling errors and under-grading in more than one third of cases (Epstein et al. 2012)), this parameter was replaced by the original preoperative biopsy Gleason grade in Scenario 4. The results of this analysis show that an independent prognostic role of TFAP2D measurement was limited to the pre-surgical scenario 4 in all cancers and ERG negative cancers (Table $4, p=0.0007$ each).

\section{Discussion}

The results of our study demonstrate that nuclear TFAP2D protein expression is a predictor of poor prognosis in ERG negative prostate cancer.

Nuclear TFAP2D staining was seen in $75.7 \%$ of 13,545 interpretable prostate cancers whereas adjacent normal prostatic epithelial cells were only occasionally TFAP2D positive. This suggests TFAP2D to be overexpressed during prostate cancer development. Published immunohistochemical studies on TFAP2D are currently lacking. Available RNA expression data from The Cancer Genome Atlas (TCGA) shown on the Human Protein Atlas website (https://www.proteinatlas.org/ENSG000000081 97-TFAP2D/pathology) do currently not support a prognostic role of TFAP2D mRNA expression. However, 


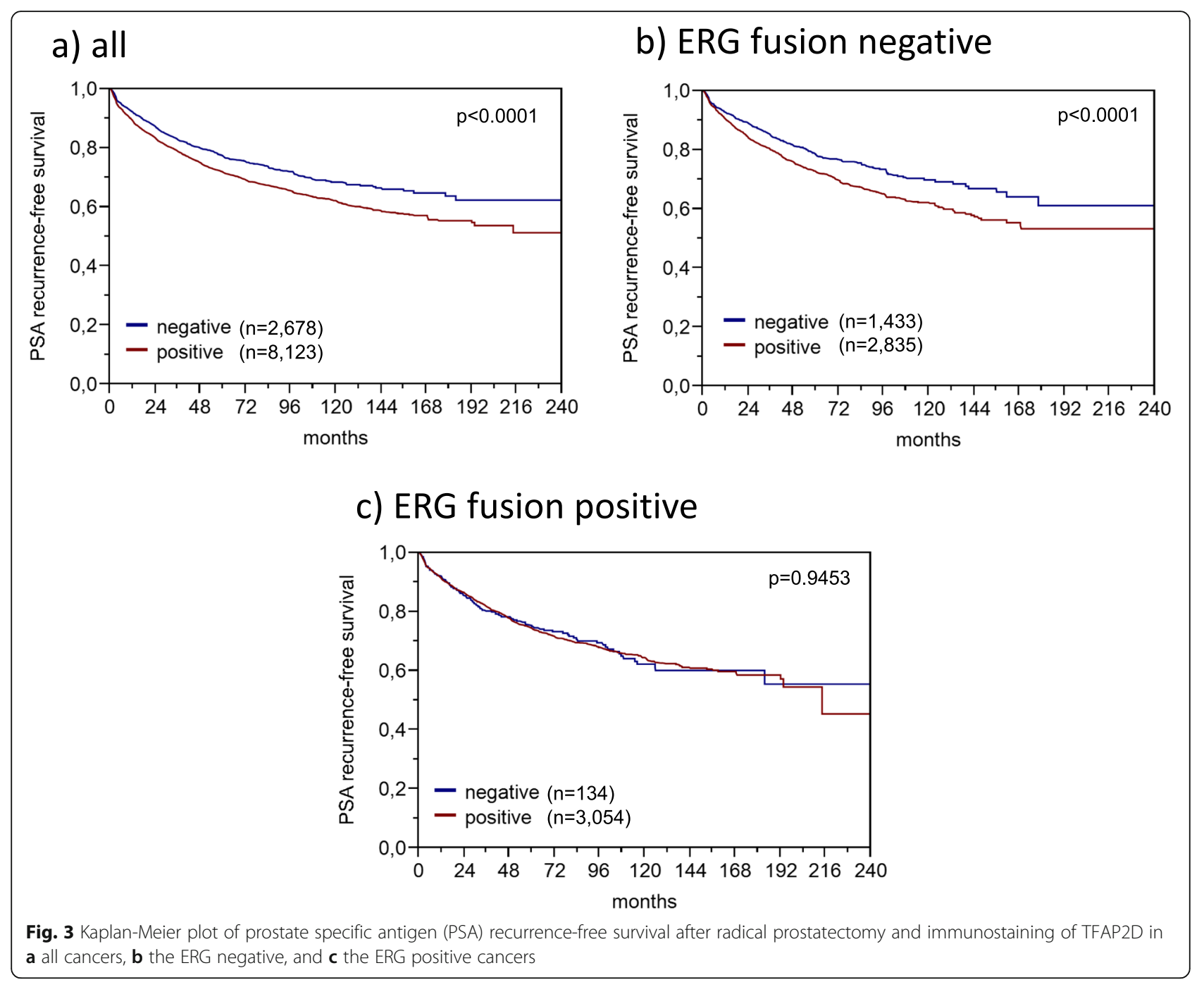

several other AP-2 family members have been reported to be differentially expressed in tumors. These include studies in prostate cancer where AP- $2 \alpha$ was described to be downregulated in prostate cancer as compared to non-tumorous tissue by Ruiz et al. (Ruiz et al. 2001). AP- $2 \gamma$ levels are increased in breast cancer cells in contrast to adjacent non-tumorous tissue (Turner et al. 1998; Pellikainen et al. 2004) and germ cell tumors show strong AP-2 $\gamma$ staining in contrast to non-neoplastic testicular tissue (Pauls et al. 2005; Hoei-Hansen et al. 2004). A role of AP-2 family members in cancer development has also been supported by functional studies showing oncogenic activity and interaction with important cancer pathways. Overexpression of AP- $2 \gamma$ promotes tumorigenesis in a murine breast cancer model, suggesting an oncogenic role of AP2 $\gamma$ in breast cancer (Jager et al. 2005). AP- $2 \alpha$ and AP- $2 \beta$ regulate cKIT through an AP-2 binding site in a tumor suppressive manner in melanoma cell lines (Huang et al. 1998). AP- $2 \alpha$ can confer tumor-suppressive properties via enhancing p53- mediated transcriptional activity (McPherson et al. 2002). The significant association of elevated TFAP2D expression levels with unfavorable prostate cancer phenotype and prognosis supports an in vivo role of TFAP2D in prostate cancer progression. Lipponen et al. earlier demonstrated increased nuclear expression of AP- $2 \alpha$ to be associated with aggressive tumor phenotype in prostate cancer (Lipponen et al. 2000).

TFAP2D is not an extensively studied protein. The molecular database collected through earlier studies on the same patient cohort enabled us to study the in vivo relationship between TFAP2D expression and molecular parameters of interest. For this study, we had selected androgen receptor protein expression because of its pivotal role in prostate cancer, TMPRSS2:ERG fusion because this is the most common molecular alteration in prostate cancer, 11 different chromosomal deletions because these represent the most common recurrent genomic alterations in prostate cancer after TMPRSS2:ERG fusions, and tumor cell proliferation (Ki-67 labeling 
a)

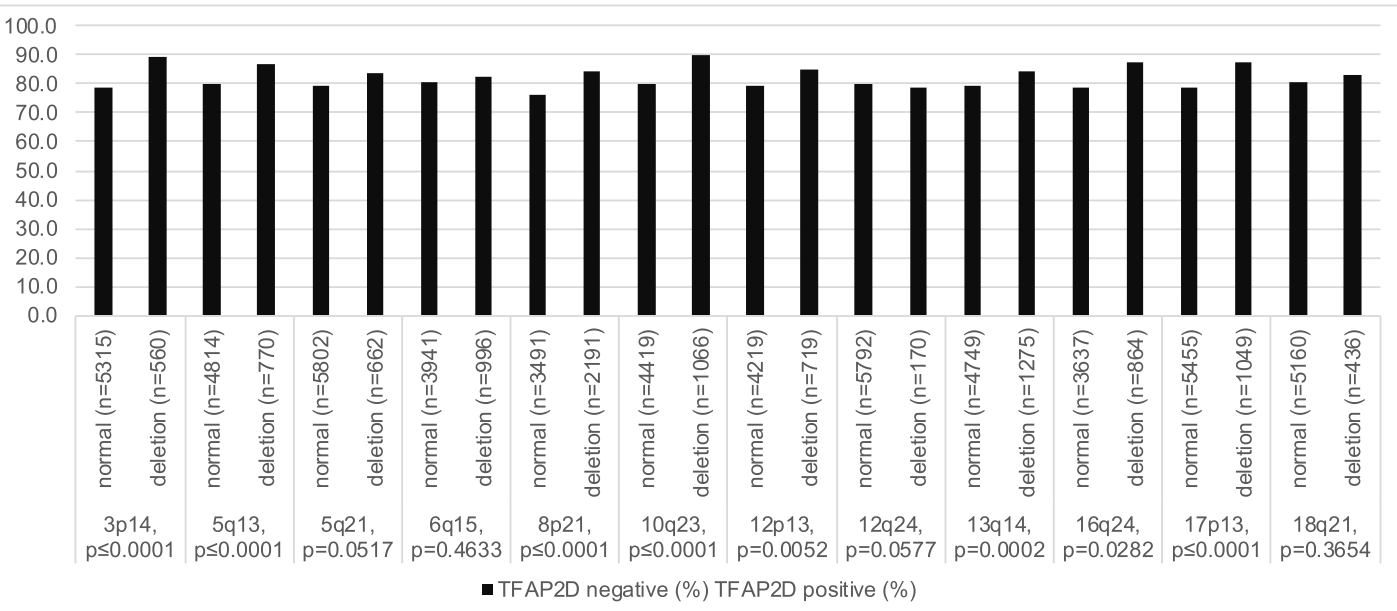

b)

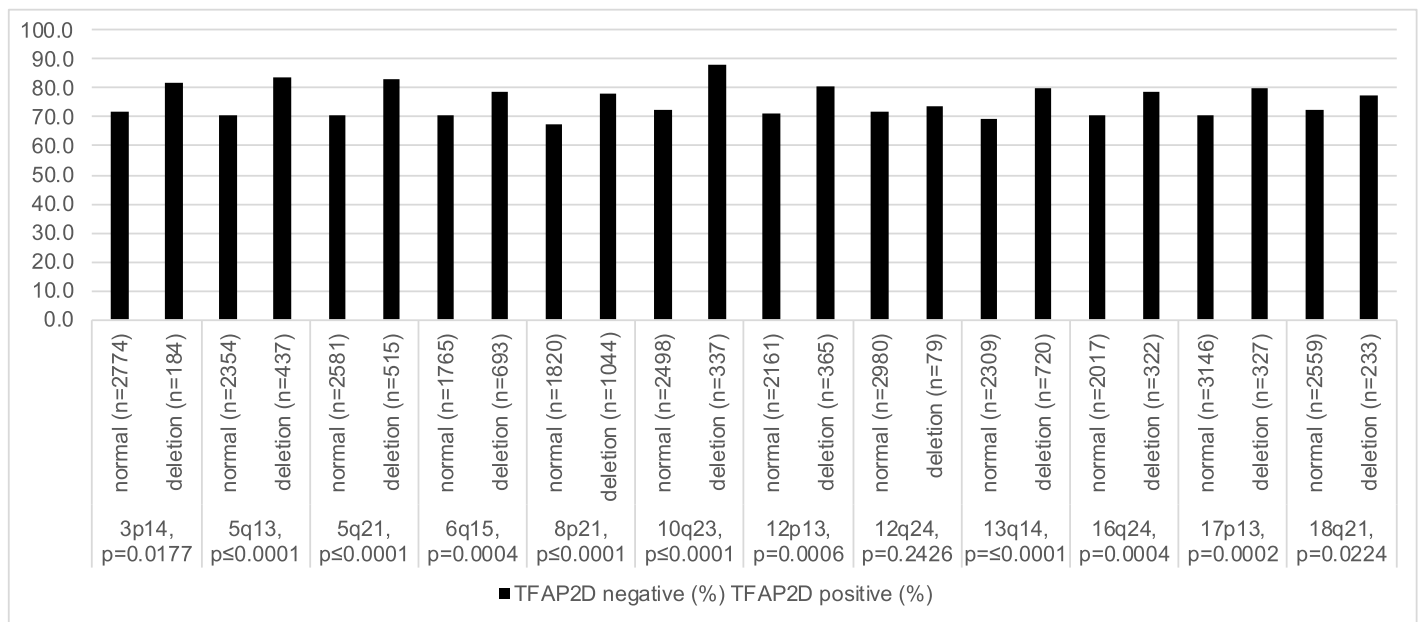

c)

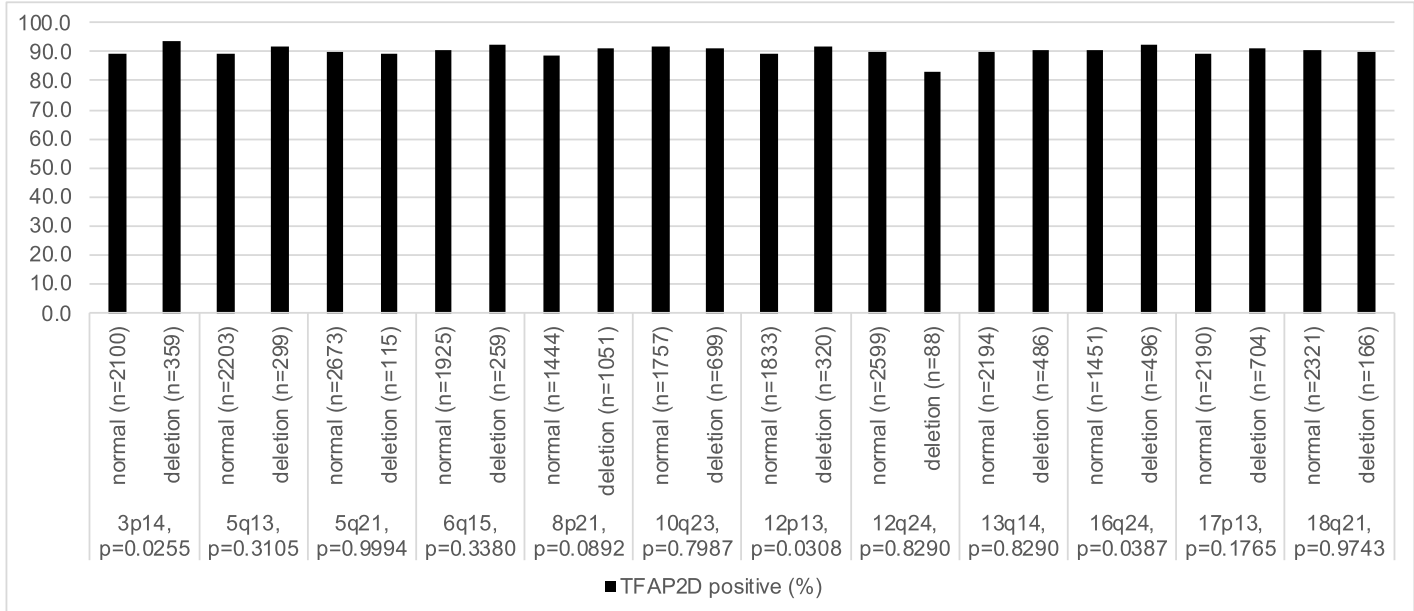

Fig. 4 TFAP2D immunostaining and common genetic deletions in a all cancers, b ERG-negative cancers, and c ERG-positive cancers 
Table 3 TFAP2D immunostaining and Ki67 labeling index

\begin{tabular}{|c|c|c|c|c|c|}
\hline \multirow{2}{*}{$\frac{k i 67}{\text { all } p<0.0001}$} & \multirow{2}{*}{$\frac{\text { TFAP2D }}{\text { negative }}$} & \multirow{2}{*}{$\begin{array}{l}n= \\
1376\end{array}$} & \multicolumn{2}{|c|}{ Ki67 Li (mean) } & \multirow{2}{*}{$\begin{array}{l}\text { standard error of the mear } \\
0.07\end{array}$} \\
\hline & & & 1.89 & \pm & \\
\hline & positive & 4328 & 3.08 & \pm & 0.04 \\
\hline \multirow[t]{2}{*}{ Gleason $\leq 3+3 p<0.0001$} & negative & 357 & 1.55 & \pm & 0.11 \\
\hline & positive & 808 & 2.51 & \pm & 0.07 \\
\hline \multirow[t]{2}{*}{ Gleason $3+4 p<0.0001$} & negative & 730 & 1.81 & \pm & 0.09 \\
\hline & positive & 2483 & 2.91 & \pm & 0.05 \\
\hline \multirow[t]{2}{*}{ Gleason $3+4$ Tert. $5 p<0.0001$} & negative & 61 & 2.10 & \pm & 0.32 \\
\hline & positive & 172 & 3.59 & \pm & 0.19 \\
\hline \multirow[t]{2}{*}{ Gleason $4+3 p=0.0025$} & negative & 112 & 2.44 & \pm & 0.30 \\
\hline & positive & 435 & 3.45 & \pm & 0.15 \\
\hline \multirow[t]{2}{*}{ Gleason $4+3$ Tert. $5 p<0.0001$} & negative & 59 & 2.12 & \pm & 0.49 \\
\hline & positive & 233 & 4.33 & \pm & 0.25 \\
\hline \multirow[t]{2}{*}{ Gleason $\geq 4+4 p=0.0504$} & negative & 56 & 3.57 & \pm & 0.61 \\
\hline & positive & 194 & 4.94 & \pm & 0.33 \\
\hline
\end{tabular}

index). TMPRSS2:ERG fusions affect about $50 \%$ of prostate cancers (Brase et al. 2011; Tomlins et al. 2008) and lead to a constitutive overexpression of the transcription factor ERG. ERG expression completely lacks prognostic relevance (Minner et al. 2011). However, ERG modulates the expression of more than 1600 genes in prostate epithelial cells. The biological effects of various proteins may be mitigated or intensified in such a modified cellular microenvironment. The increased frequency of TFAP2D positive cancers in ERG positive $(90 \%)$ compared to ERG negative subsets (74\%) suggests an interaction between ERG and TFAP2D, either directly or via modulation of shared common downstream targets. The Wnt signaling cascade, whose ERG-dependent activation has extensively been analyzed (Brase et al. 2011; Wu et al. 2013; Li et al. 2011) may connect the TMPRSS2: ERG fusion status to TFAP2D expression. In a study on human colorectal cancer cell lines the Wnt pathway was found to be affected by AP2 family members in a direct manner via protein interaction (Li and Dashwood 2004).

The strong association of TFAP2D with androgen receptor expression is consistent with previous reports describing hormone-receptor mediated effects of other AP2 family members. For instance, AP-2 binding sites are

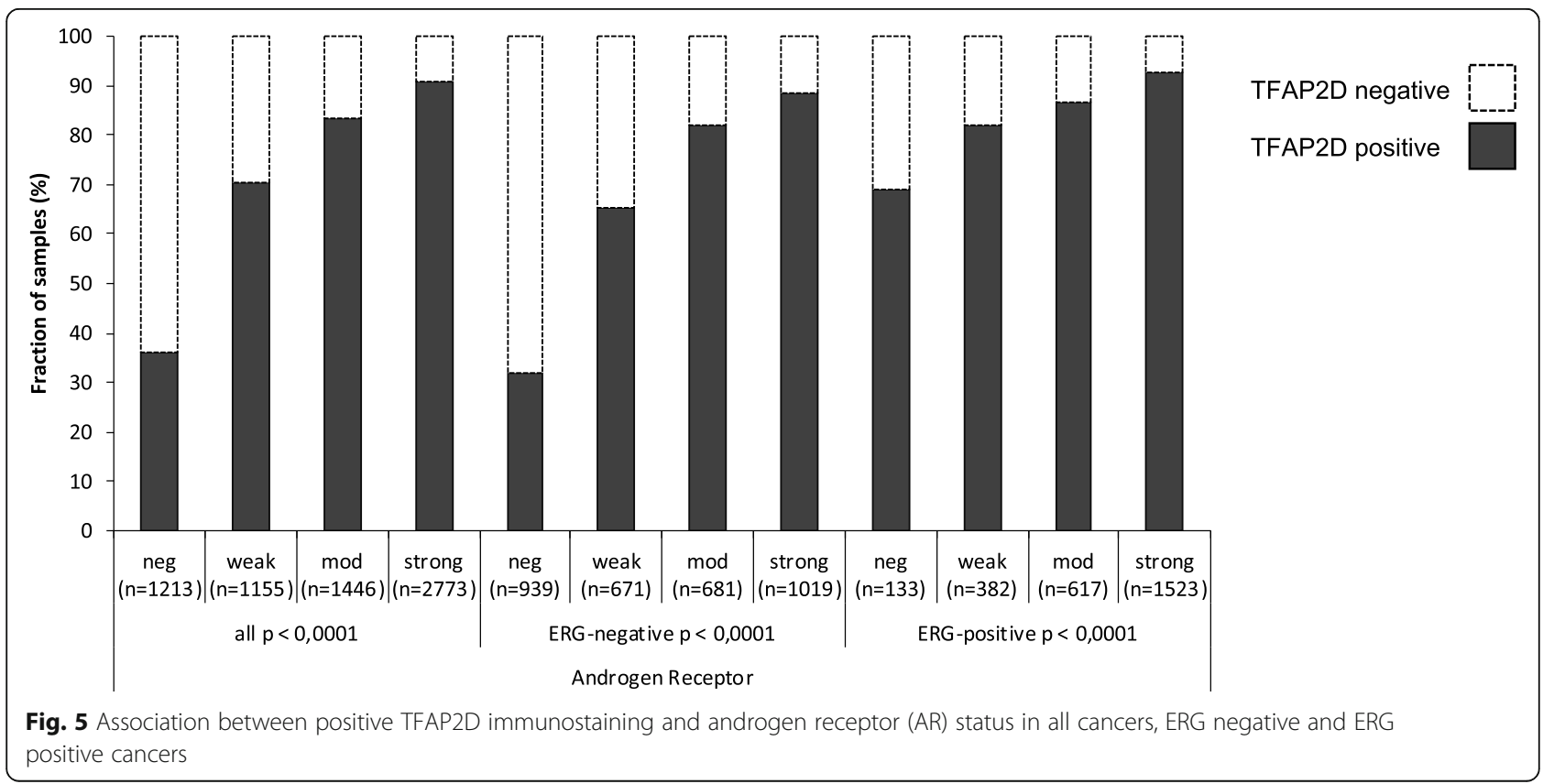


Table 4 Multivariate Cox regression analysis including established prognostic parameters and the TFAP2D expression in all prostate cancers and in the subsets of ERG negative and ERG positive prostate cancers

\begin{tabular}{|c|c|c|c|c|c|c|c|c|c|c|}
\hline \multirow[t]{2}{*}{ Tumor subset } & \multirow[t]{2}{*}{ Scenario } & \multirow[t]{2}{*}{$n$} & \multicolumn{8}{|l|}{$p$-value } \\
\hline & & & $\begin{array}{l}\text { preoperative } \\
\text { PSA-Level }\end{array}$ & pT Stage & cT Stage & $\begin{array}{l}\text { Gleason grade } \\
\text { prostatectomy }\end{array}$ & $\begin{array}{l}\text { Gleason grade } \\
\text { biopsy }\end{array}$ & $\mathrm{pN}$ stage & R status & $\begin{array}{l}\text { TFAP2D } \\
\text { Expression }\end{array}$ \\
\hline \multirow[t]{4}{*}{ all cancers } & 1 & 10,827 & $<.0001^{*}$ & $<.0001^{*}$ & - & $<.0001^{*}$ & - & $<.0001^{*}$ & $<.0001^{*}$ & 0.2379 \\
\hline & 2 & 10,846 & $<.0001^{*}$ & $<.0001^{*}$ & - & $<.0001^{*}$ & - & - & $<.0001^{*}$ & 0.2712 \\
\hline & 3 & 10,692 & $<.0001^{*}$ & - & $<.0001^{*}$ & $<.0001^{*}$ & - & - & - & $0.0496^{*}$ \\
\hline & 4 & 9204 & $<.0001^{*}$ & - & $<.0001^{*}$ & - & $<.0001^{*}$ & - & - & $0.0007^{*}$ \\
\hline \multirow[t]{4}{*}{ ERG-negative cancers } & 1 & 4327 & $<.0001^{*}$ & $<.0001^{*}$ & - & $<.0001^{*}$ & - & 0.8751 & $<.0001^{*}$ & 0.4114 \\
\hline & 2 & 4334 & $<.0001^{*}$ & $<.0001^{*}$ & - & $<.0001^{*}$ & - & - & $0.0040^{*}$ & 0.4285 \\
\hline & 3 & 4298 & $<.0001^{*}$ & - & $<.0001^{*}$ & $<.0001^{*}$ & - & - & - & 0.1722 \\
\hline & 4 & 4228 & $<.0001^{*}$ & - & $<.0001^{*}$ & - & $<.0001^{*}$ & - & - & $0.0007^{*}$ \\
\hline \multirow[t]{4}{*}{ ERG-postive cancers } & 1 & 3429 & $<.0001^{*}$ & $<.0001^{*}$ & - & $<.0001^{*}$ & - & $<.0001^{*}$ & $0.0001^{*}$ & 0.61 \\
\hline & 2 & 3437 & $<.0001^{*}$ & $<.0001^{*}$ & - & $<.0001^{*}$ & - & - & $<.0001^{*}$ & 0.822 \\
\hline & 3 & 3383 & $<.0001^{*}$ & - & $<.0001^{*}$ & $<.0001^{*}$ & - & - & - & 0.8684 \\
\hline & 4 & 3327 & $<.0001^{*}$ & - & $<.0001^{*}$ & - & $<.0001^{*}$ & - & - & 0.2301 \\
\hline
\end{tabular}

Scenario 1 includes all postoperatively available parameters (pathological tumor (pT) stage, lymph node (pN), surgical margin (R) status, preoperative PSA value and Gleason grade obtained after the morphological evaluation of the entire resected prostate. Scenario 2 excluded the nodal status from analysis. Scenario 3 included preoperative PSA, clinical tumor (cT) stage and Gleason grade obtained on the prostatectomy specimen. In scenario 4, the preoperative Gleason grade obtained on the original biopsy was combined with preoperative PSA, and cT stage (* significant)

present in the promotor of the estrogen receptor which has implications for breast and endometrial cancer (Lin et al. 2016; Woodfield et al. 2009). A direct effect of TFAP2D via AP-2 binding sites within the androgen receptor gene is not known, however the epigenetic regulator protein EZH2 may link androgen-dependent and TFAP2D pathways. Beyond silencing gene expression via its histone methyltransferase activity, EZH2 can directly coactivate the androgen receptor and other transcription factors in prostate cancer (Xu et al. 2012). The promotor region of TFAP2D harbors EZH2 binding sites (Fishilevich et al. 2017). As cellular proliferation is dependent on the androgen receptor function in prostate cancer, it is possible, that the significant link between elevated Ki67 labeling index and high TFAP2D expression is also androgen receptor driven.

Our analysis of molecularly defined tumor subgroups revealed that the prognostic impact of TFAP2D expression was almost entirely driven by ERG negative cases. That an independent prognostic role of TFAP2D was limited to the pre-surgical situation underscores the prognostic power of classical post-surgical parameters such as the Gleason score that are difficult to beat for a molecular marker. An ERG specific cellular microenvironment may be responsible for the particularly prognostic role of TFAP2D-expression in ERG negative cancers or the mitigation of it in ERG negative cancers. It is not uncommon that the prognostic value of molecular features are limited to ERG positive (Burdelski et al. 2015; Burdelski et al. 2016a; Melling et al. 2015) or ERG negative cancers (Heumann et al. 2017; Burdelski et al. 2016b; Heumann et al. 2018). It should be kept in mind that the ERG dependent differences in prognostic value could be caused by the experimental set-up. The number of TFAP2D negative cases was rather low in the ERG positive subgroup $(n=134)$ for PSA recurrence. It cannot be excluded that the immunohistochemistry protocol developed for this project was better suited to distinguish expression differences in cancers with somewhat lower expression levels such as in ERG negative cancers than in tumors with higher expression, such as in ERG positive cancers. Irrespective of the reason behind, the selective prognostic impact of TFAP2D in ERG negative cancers demonstrates that prognostic markers (or their defining thresholds) depend on other molecular tumor features and the intracellular microenvironment of cancer cells. This represents a challenge for the development of prognostic cancer tests that shall be applicable to every patient.

Most chromosomal deletions occurring in prostate cancer are linked to either positive (PTEN, 3p, 8p, 16q, 17p) (Krohn et al. 2013; Kluth et al. 2017; Krohn et al. 2012; Kluth et al. 2015b; Kluth et al. 2014) or negative (6q, 5q, 13q, 18q) (Burkhardt et al. 2013; Kluth et al. 2013; Kluth et al. 2018; Kluth et al. 2016) ERG status. The evaluation whether a relationship exists between deletions and the expression of proteins that are also ERG related must therefore be done in subgroups of ERG positive and ERG negative cancers. That elevated TFAP2D expression was significantly associated with the majority of the analyzed deletions in ERG negative cancers highlights that elevated TFAP2D levels are either a 
cause or a consequence of genomic instability in prostate cancer cells. The transcriptional program of TFAP2D indeed affects genes with a role in DNA repair such as MMS19, a key player of nucleotide excision repair (Sun et al. 2007). That the association between TFAP2D expression levels and chromosomal deletions was visible in ERG negative but not in ERG positive cancers could again be explained by a biological role of the ERG related intracellular microenvironment on TFAP2D function or by issues related to the experimental set-up.

Moreover, the complete lack of a tendency towards a different outcome between TFAP2D positive and negative cancers defined by a specific classical or quantitative Gleason grade demonstrates the power of traditional morphologic parameters if it comes to predicting patient outcome. This represents another considerable challenge for the development of molecular prognostic parameters. It is noteworthy, however, that the Gleason Grade suffers from substantial interobserver variability reaching up to $40 \%$ in individual biopsies (Sauter et al. 2016). It is thus desirable not only to find independent but also better reproducible prognostic markers as compared to established parameters.

Some limitations are connected to our study. First, only one $0.6 \mathrm{~mm}$ tissue spot has been analyzed per cancer. Because prostate cancer is typically multifocal and heterogeneous, it cannot be excluded that the $75 \%$ TFAP2D positivity still underestimate the real frequency. However, using TMAs with a single spot per cancer, we have been able to reproduce a multitude of established associations between clinical features and molecular markers such as HER2 (Barlund et al. 2000), Vimentin (Moch et al. 1999) and Ki67 (Ruiz et al. 2006) in the past. Second, only one pathologist analyzed the TMA. We do not consider this as a serious drawback of our study. This is based on our finding that the experimental conditions in IHC studies have a much higher impact on the study outcome than for interobserver variability. For example, we have previously shown that the fraction of cancers staining positive for p53 can vary between 2.5 and $>90 \%$ if an "oversensitive" staining protocol was used (Schlomm et al. 2008). Third, we did not study TFAP2D in presurgical core needle biopsies but compared post prostatectomy IHC findings with pre-surgical clinical and histological parameters in our multivariate analysis. It is of note that the small amount of tissue in a $0.6 \mathrm{~mm}$ spot resembles that of core needle biopsies, making our TMA approach a suitable model for punch biopsy analysis.

\section{Conclusions}

Upregulation of TFAP2D parallels genomic instability in prostate cancer and is associated with adverse tumor features, rapid cell proliferation and poor patient prognosis. If TFAP2D expression analysis will have a role for prostate cancer prognosis assessment, this will most likely be in combination with other biomarkers.

\section{Supplementary information}

Supplementary information accompanies this paper at https://doi.org/10. 1186/s10020-020-00148-4.

Additional file 1: Figure $\mathbf{S 1}$. Prognostic impact of TFAP2D expression in all cancers defined by the Gleason score. a) Impact of negative and positive TFAP2D expression as compared to the classical Gleason score categories. b-h) Impact of negative and positive TFAP2D expression as compared to the quantitative Gleason score categories defined by subsets of cancers with b) $\leq 5 \%$ Gleason 4 patterns, c) 6-10\% Gleason 4 patterns, d) 11-20\% Gleason 4 patterns, e) 21-30\% Gleason 4 patterns, f) $31-49 \%$ Gleason 4 patterns, g) 50-60\% Gleason 4 patterns, h) $\geq 61 \%$ Gleason 4 patterns.

\section{Abbreviations}

AR: Androgen receptor; ERG: ETS-related gene; ETS: E26 transformationspecific; EZH2: Enhancer of zeste homolog 2; PSA: Prostate specific antigen; PTEN: Phosphatase and Tensin homolog; TFAP2D: Transcriptions factor AP28; TMA: Tissue microarray; TMPRSS2: Transmembrane protease, serine 2; UICC: International Union Against Cancer

\section{Acknowledgements}

We are grateful to Inge Brandt, Melanie Witt, Maren Eisenberg and Sünje Seekamp for excellent technical assistance.

\section{Authors' contributions}

Christoph Fraune, Luisa Harms, Ronald Simon, Doris Höflmayer, Katharina Möller, Sören Weidemann, Till Clauditz, Claudia Hube-Magg, Cornelia Schroeder contributed to conception, design, data collection, data analysis and manuscript writing. Christoph Fraune; Luisa Harms, Maria C Tsourlakis, Franziska Büscheck: immunohistochemistry analysis. Markus Graefen, Hartwig Huland, Hans Heinzer, Alexander Haese, Thorsten Schlomm: conception and design, collection of samples. Andreas Lübcke, Christina Möller-Koop, Patrick Lebock, David Dum, Stefan Steurer, Simon Kind, Sarah Minner: data collection and data analysis. Jakob R Izbicki, Ronald Simon, Guido Sauter, Cornelia Schroeder: study supervision. The author(s) read and approved the final manuscript.

\section{Funding}

This work was supported by the Federal Ministry for Education and Research of Germany (BMBF) (grant no. 01ZX1602C) to GS. The funding body had no involvement in the design of the study, collection, analysis, and interpretation of data and in writing the manuscript.

\section{Availability of data and materials}

All data generated or analyzed during this study are included in this published article [and its supplementary information files].

\section{Ethics approval and consent to participate}

The usage of archived diagnostic left-over tissues for manufacturing of tissue microarrays, their analysis for research purposes and patient data analysis has been approved by local laws $(\mathrm{HmbKHG}, \S 12,1)$ and by the local ethics committee (Ethics commission Hamburg, WF-049/09). All work has been carried out in compliance with the Helsinki Declaration.

\section{Consent for publication}

Not applicable.

\section{Competing interests}

The authors declare that they have no competing interests.

\section{Author details}

${ }^{1}$ Institute of Pathology, University Medical Center Hamburg-Eppendorf, Martinistr 52, 20246 Hamburg, Germany. ${ }^{2}$ General, Visceral and Thoracic Surgery Department and Clinic, University Medical Center Hamburg-Eppendorf, Hamburg, Germany. ${ }^{3}$ Department of Urology, Charité - 
Universitätsmedizin Berlin, Berlin, Germany. ${ }^{4}$ Martini-Clinic, Prostate Cancer Center, University Medical Center Hamburg-Eppendorf, Hamburg, Germany.

\section{Received: 12 November 2019 Accepted: 13 February 2020 Published online: 06 March 2020}

\section{References}

Barlund $\mathrm{M}$, Forozan F, Kononen J, Bubendorf L, Chen Y, Bittner ML, et al. Detecting activation of ribosomal protein $\mathbf{S}$ kinase by complementary DNA and tissue microarray analysis. J Natl Cancer Inst. 2000;92:1252-9.

Bosher JM, Totty NF, Hsuan JJ, Williams T, Hurst HC. A family of AP-2 proteins regulates c-erbB-2 expression in mammary carcinoma. Oncogene. 1996;13: $1701-7$.

Brase JC, Johannes M, Mannsperger H, Falth M, Metzger J, Kacprzyk LA, et al. TMPRSS2-ERG -specific transcriptional modulation is associated with prostate cancer biomarkers and TGF-beta signaling. BMC Cancer. 2011;11:507.

Bray F, Ferlay J, Soerjomataram I, Siegel RL, Torre LA, Jemal A. Global cancer statistics 2018: GLOBOCAN estimates of incidence and mortality worldwide for 36 cancers in 185 countries. CA Cancer J Clin. 2018;68:394-424.

Burdelski C, Bujupi E, Tsourlakis MC, Hube-Magg C, Kluth M, Melling N, et al. Loss of SOX9 expression is associated with PSA recurrence in ERG-positive and PTEN deleted prostate cancers. PLoS One. 2015;10:e0128525.

Burdelski C, Dieckmann T, Heumann A, Hube-Magg C, Kluth M, Beyer B, et al. p16 upregulation is linked to poor prognosis in ERG negative prostate cancer. Tumour Biol. 2016b;37:12655-63.

Burdelski C, Kleinhans S, Kluth M, Hube-Magg C, Minner S, Koop C, et al. Reduced AZGP1 expression is an independent predictor of early PSA recurrence and associated with ERG-fusion positive and PTEN deleted prostate cancers. Int J Cancer. 2016a;138:1199-206.

Burkhardt L, Fuchs S, Krohn A, Masser S, Mader M, Kluth M, et al. CHD1 is a 5 q2 tumor suppressor required for ERG rearrangement in prostate cancer. Cancer Res. 2013;73:2795-805.

Cheng C, Ying K, Xu M, Zhao W, Zhou Z, Huang Y, et al. Cloning and characterization of a novel human transcription factor AP-2 beta like gene (TFAP2BL1). Int J Biochem Cell Biol. 2002;34:78-86.

Eckert D, Buhl S, Weber S, Jager R, Schorle H. The AP-2 family of transcription factors. Genome Biol. 2005;6:246.

Epstein Jl, Feng Z, Trock BJ, Pierorazio PM. Upgrading and downgrading of prostate cancer from biopsy to radical prostatectomy: incidence and predictive factors using the modified Gleason grading system and factoring in tertiary grades. Eur Urol. 2012;61:1019-24.

Feng W, Williams T. Cloning and characterization of the mouse AP-2 epsilon gene: a novel family member expressed in the developing olfactory bulb. Mol Cell Neurosci. 2003;24:460-75.

Fishilevich S, Nudel R, Rappaport N, Hadar R, Plaschkes I, Iny Stein T, et al. GeneHancer: genome-wide integration of enhancers and target genes in GeneCards. Database (Oxford). 2017;2017:1-17.

Heumann A, Heinemann N, Hube-Magg C, Lang DS, Grupp K, Kluth M, et al. High $B C A R 1$ expression is associated with early PSA recurrence in ERG negative prostate cancer. BMC Cancer. 2018;18:37.

Heumann A, Kaya O, Burdelski C, Hube-Magg C, Kluth M, Lang DS, et al. Up regulation and nuclear translocation of $\mathrm{Y}$-box binding protein 1 (YB-1) is linked to poor prognosis in ERG-negative prostate cancer. Sci Rep. 2017;7: 2056.

Hoei-Hansen CE, Nielsen JE, Almstrup K, Sonne SB, Graem N, Skakkebaek NE, et al. Transcription factor AP-2gamma is a developmentally regulated marker of testicular carcinoma in situ and germ cell tumors. Clin Cancer Res. 2004; 10:8521-30.

Huang S, Jean D, Luca M, Tainsky MA, Bar-Eli M. Loss of AP-2 results in downregulation of C-KIT and enhancement of melanoma tumorigenicity and metastasis. EMBO J. 1998;17:4358-69.

Jager R, Friedrichs N, Heim I, Buttner R, Schorle H. Dual role of AP-2gamma in ErbB-2-induced mammary tumorigenesis. Breast Cancer Res Treat. 2005;90: 273-80.

Kluth M, Ahrary R, Hube-Magg C, Ahmed M, Volta H, Schwemin C, et al. Genomic deletion of chromosome 12p is an independent prognostic marker in prostate cancer. Oncotarget. 2015a;6:27966-79.

Kluth M, Amschler NN, Galal R, Moller-Koop C, Barrow P, Tsourlakis MC, et al. Deletion of $8 \mathrm{p}$ is an independent prognostic parameter in prostate cancer. Oncotarget. 2017:8:379-92.
Kluth M, Graunke M, Moller-Koop C, Hube-Magg C, Minner S, Michl U, et al. Deletion of $18 \mathrm{q}$ is a strong and independent prognostic feature in prostate cancer. Oncotarget. 2016;7:86339-49.

Kluth M, Harasimowicz S, Burkhardt L, Grupp K, Krohn A, Prien K, et al. Clinical significance of different types of $p 53$ gene alteration in surgically treated prostate cancer. Int J Cancer. 2014;135:1369-80.

Kluth M, Hesse J, Heinl A, Krohn A, Steurer S, Sirma H, et al. Genomic deletion of MAP 3K7 at 6q12-22 is associated with early PSA recurrence in prostate cancer and absence of TMPRSS2:ERG fusions. Mod Pathol. 2013;26:975-83.

Kluth M, Runte F, Barow P, Omari J, Abdelaziz ZM, Paustian L, et al. Concurrent deletion of $16 \mathrm{q} 23$ and PTEN is an independent prognostic feature in prostate cancer. Int J Cancer. 2015b;137:2354-63.

Kluth M, Scherzai S, Buschek F, Fraune C, Moller K, Hoflmayer D, et al. 13q deletion is linked to an adverse phenotype and poor prognosis in prostate cancer. Genes Chromosomes Cancer. 2018:57:504-12.

Kononen J, Bubendorf L, Kallioniemi A, Barlund M, Schraml P, Leighton S, et al. Tissue microarrays for high-throughput molecular profiling of tumor specimens. Nat Med. 1998;4:844-7.

Krohn A, Diedler T, Burkhardt L, Mayer PS, De Silva C, Meyer-Kornblum M, et al. Genomic deletion of PTEN is associated with tumor progression and early PSA recurrence in ERG fusion-positive and fusion-negative prostate cancer. Am J Pathol. 2012;181:401-12.

Krohn A, Seidel A, Burkhardt L, Bachmann F, Mader M, Grupp K, et al. Recurrent deletion of 3p13 targets multiple tumour suppressor genes and defines a distinct subgroup of aggressive ERG fusion-positive prostate cancers. J Pathol. 2013;231:130-41.

Li Q, Dashwood RH. Activator protein 2alpha associates with adenomatous polyposis coli/beta-catenin and Inhibits beta-catenin/T-cell factor transcriptional activity in colorectal cancer cells. J Biol Chem. 2004;279: 45669-75.

Li Y, Kong D, Wang Z, Ahmad A, Bao B, Padhye S, et al. Inactivation of AR/ TMPRSS2-ERG/Wnt signaling networks attenuates the aggressive behavior of prostate cancer cells. Cancer Prev Res (Phila). 2011;4:1495-506.

Lin CY, Chao A, Wang TH, Lee LY, Yang LY, Tsai CL, et al. Nucleophosmin/B23 is a negative regulator of estrogen receptor alpha expression via AP2gamma in endometrial cancer cells. Oncotarget. 2016;7:60038-52.

Lipponen P, Aaltomaa S, Kellokoski J, Ala-Opas M, Kosma V. Expression of activator protein 2 in prostate cancer is related to tumor differentiation and cell proliferation. Eur Urol. 2000;37:573-8.

McPherson LA, Loktev AV, Weigel RJ. Tumor suppressor activity of AP2alpha mediated through a direct interaction with p53. J Biol Chem. 2002;277: 45028-33.

Melling N, Harutyunyan L, Hube-Magg C, Kluth M, Simon R, Lebok P, et al. Highlevel HOOK3 expression is an independent predictor of poor prognosis associated with genomic instability in prostate Cancer. PLoS One. 2015;10: e0134614.

Minner S, Enodien M, Sirma H, Luebke AM, Krohn A, Mayer PS, et al. ERG status is unrelated to PSA recurrence in radically operated prostate cancer in the absence of antihormonal therapy. Clin Cancer Res. 2011;17:5878-88.

Minner S, Jessen B, Stiedenroth L, Burandt E, Kollermann J, Mirlacher M, et al. Low level HER2 overexpression is associated with rapid tumor cell proliferation and poor prognosis in prostate cancer. Clin Cancer Res. 2010;16: $1553-60$.

Moch H, Schraml P, Bubendorf L, Mirlacher M, Kononen J, Gasser T, et al. Highthroughput tissue microarray analysis to evaluate genes uncovered by CDNA microarray screening in renal cell carcinoma. Am J Pathol. 1999;154:981-6.

Moser M, Pscherer A, Roth C, Becker J, Mucher G, Zerres K, et al. Enhanced apoptotic cell death of renal epithelial cells in mice lacking transcription factor AP-2beta. Genes Dev. 1997b;11:1938-48.

Moser M, Ruschoff J, Buettner R. Comparative analysis of AP-2 alpha and AP-2 beta gene expression during murine embryogenesis. Dev Dyn. 1997a;208: $115-24$.

Pauls K, Jager R, Weber S, Wardelmann E, Koch A, Buttner R, et al. Transcription factor AP-2gamma, a novel marker of gonocytes and seminomatous germ cell tumors. Int J Cancer. 2005;115:470-7.

Pellikainen J, Naukkarinen A, Ropponen K, Rummukainen J, Kataja V, Kellokoski J, et al. Expression of HER2 and its association with AP-2 in breast cancer. Eur J Cancer 2004:40:1485-95.

Ruiz C, Seibt S, Al Kuraya K, Siraj AK, Mirlacher M, Schraml P, et al. Tissue microarrays for comparing molecular features with proliferation activity in breast cancer. Int J Cancer. 2006;118:2190-4. 
Ruiz M, Troncoso P, Bruns C, Bar-Eli M. Activator protein 2alpha transcription factor expression is associated with luminal differentiation and is lost in prostate cancer. Clin Cancer Res. 2001;7:4086-95.

Sauter G, Steurer S, Clauditz TS, Krech T, Wittmer C, Lutz F, et al. Clinical utility of quantitative Gleason grading in prostate biopsies and prostatectomy specimens. Eur Urol. 2016;69:592-8.

Schlomm T, Iwers L, Kirstein P, Jessen B, Kollermann J, Minner S, et al. Clinical significance of $p 53$ alterations in surgically treated prostate cancers. Mod Pathol. 2008;21:1371-9.

Sun L, Huang S, Wu Q, Gu S, Fu X, Yu K, et al. Identification of genes differentially regulated by transcription factor, AP-2delta. Front Biosci. 2007;12:1699-706.

Tomlins SA, Laxman B, Varambally S, Cao X, Yu J, Helgeson BE, et al. Role of the TMPRSS2-ERG gene fusion in prostate cancer. Neoplasia. 2008;10:177-88.

Turner BC, Zhang J, Gumbs AA, Maher MG, Kaplan L, Carter D, et al. Expression of AP-2 transcription factors in human breast cancer correlates with the regulation of multiple growth factor signalling pathways. Cancer Res. 1998; 58:5466-72.

Weischenfeldt J, Simon R, Feuerbach L, Schlangen K, Weichenhan D, Minner S, et al. Integrative genomic analyses reveal an androgen-driven somatic alteration landscape in early-onset prostate cancer. Cancer Cell. 2013;23:159-70.

Werling U, Schorle H. Transcription factor gene AP-2 gamma essential for early murine development. Mol Cell Biol. 2002;22:3149-56.

Williams T, Tjian R. Characterization of a dimerization motif in AP-2 and its function in heterologous DNA-binding proteins. Science. 1991;251:1067-71.

Woodfield GW, Hitchler MJ, Chen Y, Domann FE, Weigel RJ. Interaction of TFAP2C with the estrogen receptor-alpha promoter is controlled by chromatin structure. Clin Cancer Res. 2009;15:3672-9.

Wu L, Zhao JC, Kim J, Jin HJ, Wang CY, Yu J. ERG is a critical regulator of Wnt/ LEF1 signaling in prostate cancer. Cancer Res. 2013;73:6068-79.

Xu K, Wu ZJ, Groner AC, He HH, Cai C, Lis RT, et al. EZH2 oncogenic activity in castration-resistant prostate cancer cells is Polycomb-independent. Science. 2012;338:1465-9.

Zhao F, Lufkin T, Gelb BD. Expression of Tfap2d, the gene encoding the transcription factor Ap-2 delta, during mouse embryogenesis. Gene Expr Patterns. 2003;3:213-7.

\section{Publisher's Note}

Springer Nature remains neutral with regard to jurisdictional claims in published maps and institutional affiliations.

Ready to submit your research? Choose BMC and benefit from:

- fast, convenient online submission

- thorough peer review by experienced researchers in your field

- rapid publication on acceptance

- support for research data, including large and complex data types

- gold Open Access which fosters wider collaboration and increased citations

- maximum visibility for your research: over $100 \mathrm{M}$ website views per year

At $\mathrm{BMC}$, research is always in progress.

Learn more biomedcentral.com/submissions 